\title{
Impact of Difficulties Faced by Adolescents in Making Career Decision on their Mental Health
}

\author{
Ayesha Khan ${ }^{1}$, Adeela Rehman² \\ ${ }^{1}$ Department of Behavioral Sciences, Fatima Jinnah Women University, Rawalpindi, Pakistan \\ ${ }^{2}$ Department of Sociology, Fatima Jinnah Women University, Rawalpindi, Pakistan \\ ayeshaaa6810@gmail.com
}

\begin{abstract}
This research aimed to explore the impact of difficulties faced by adolescents in making a career decision on their mental health. The objective of the research was to explore the factors affecting career decision making and to explore the psychological effect of career decision making difficulties. A quantitative research design was used to collect data through online survey by random sampling method in which a sample of 70 adolescents aged between 18-24 both male (28) and female (42) were collected from Rawalpindi, Pakistan and then analyzed on SPSS. A correlation (p: .002) was found between career indecisiveness and mental health. Independent $\mathrm{T}$ test result suggested that gender difference exists with respect to career indecisiveness indicating a value of $\mathrm{p}$ to be .01, while one way ANOVA indicated a value of $\mathrm{p}$ to be .382, showing that no significant difference exist with respect to respondents age. A chi square result indicated the factors affecting career decision making to be parental (p: .000) and peer pressure (p: .002) and indicated that career decision making time period is stressful for adolescents who feel difficulty in making a career decision (p: .000) indicating a psychological effect. Thus, the hypothesis was proved that adolescents face career decision making difficulties which negatively impact their mental health and it is recommended that they should be given career guidance to help them out in exploring what they really want to do in their lives instead of making a wrong career and regretting it later.
\end{abstract}

Keywords: Career, Decision Making, Career Indecisiveness, Mental Health. Self-efficacy, Outcome expectations

\section{Introduction}

Career is the occupation that a person selects and expects to progress in it or to look for opportunities (career, n.d) while indecisive is an inability that one faces in making a decision (indecisiveness, n.d). So career indecisiveness can be considered as a difficulty or a person's inability in making a decision regarding the occupation that one wants to pursue or progress in. Sometimes people know which field they want to pursue but they are not sure which sub field they should pursue. While in some cases they face difficulty in choosing one career over another. Many people in their life face difficulty in making a career decision at some point in their lives. One of the critical time periods is adolescence. It is the time when a child is transforming into an adult and going through a developmental phase that can involve physical as well as hormonal changes (adolescence, n.d). Adolescence becomes a critical time period where after intermediate when an individual has to choose a specific career, he is usually confused and an ambiguity surrounds him. Either he has so many opportunities or either he has very limited ones. He faces difficulty to choose a specific career or even if he chooses one, he ends up regretting it later as when he continues he feels like this is not what he really wanted to do. There is chronic indecisiveness as well as developmental and one study found out that these two are effected by self-efficacy, autonomy as well as support from friends and parents (Guay, Senécal, Gauthier \& Fernet, 2003). Apart from this there can be other factors as well that influence adolescents career decision making like parental influence, peer pressure, hormonal changes, that make it harder for them to decide anything that this research aimed to explore and look at its impact on one's mental health.

\section{Research Questions}

- What are the factors affecting career decision making?

- What are the psychological effects of career decision making difficulties?

\section{Objectives}

- To find out the factors affecting career decision making.

- To find out the psychological effects of career decision making difficulties. 
Problem Statement: Adolescence is a critical period in an individual's life specifically after intermediate, where an individual has to decide what he wants to do in his life and which career he should choose, he faces a difficulty in making a career decision. He is not able to decide which field he should go into and in which field he will be able to prosper. Due to this adolescents face psychological problem also as the pressure of not being able to decide any career and start a university affects them psychologically. This issue has been faced by the researcher herself and she has observed her own class fellows and other adolescents going through this. Intermediate is a critical time period in one's life where adolescents are pressurized to score goods or else, they will not be able to stand anywhere in their lives and get into a good field and a good university. An adolescent needs a carrier guidance that he is not given unfortunately. He has so many career options in his mind that he is not able to choose any one for him. Also, in our society so much emphasis is given to engineering and medical fields and a person is not validated for choosing some other career. Many times, adolescents want to pursue a career of their own that is usually not preferred by their parents that also leads to pressure and career confusion as they are not able to decide what actually is better for them. In all this they suffer psychologically as they are in a conflict of not being able to take any decision and no guidance is given to them as one study indicates that adolescents who face career uncertainty have low self-esteem and face difficulty in making a career decision (Lin, $\mathrm{Wu}, \&$ Chen, 2015).

\section{Literature Review}

Pamela Corey did a research in 2015 to find out the effect of parental pressure and perceived control on career exploration of adults. There were about 20 participants in the study who were students of Toronto University Canada. The participants were females of age 20-21 who were enrolled in their 2nd and 3rd year in arts and humanities subjects and they all were the ones who had experienced parental pressure or were experiencing parental pressure. The research was a qualitative method design. From the research it was found that parental pressure and perceived control negatively affect their career exploration as to make a career decision one needs to be mature enough and should have the control of making a career decision but their parents were not letting them do so (Corey, 2015). As parents have certain expectations form their children and this affects their self-esteem as well as self-efficacy that can be understood from the following research. A quantitative study was performed on students of age 18-25 in which snow ball sampling method was used. The study was done to see their confidence in their success in a particular field.

From the research it was found that there is positive correlation between peer attachment and self-efficacy as peers affect a person's capacity to make decisions. Between career decision making and self-efficacy as ones confidence that he is capable of doing certain thing influences his decision making, and a positive correlation was found between parental attachment and peer as adolescence are close to their parents as well as peers that affect them in many ways. A negative correlation was found between peer attachment and career decision making as peers affect the ability to make career decision making (Hellmann, 2014) as parents and peers affect an adolescence decision making ability. With that there are certain other factors as well that affect them as discussed below. A mixed method study was conducted in Lahore to find out the factors that affect the career choice of MS students in which 432 students were selected from two public sector universities. Questionnaires and interviews were used to take information and questionnaire consisted of 28 statements.

The result suggested that fathers having a professional degree influence their children and mothers influence them in terms of interest. Then friends affect them as they feel more confident in the field that their friends select. Media played a role as they were inspired from journalists on TV and gender related issues came as girls were restricted to a particular field. Financial constraints also affected career choices and other factors like people advices effected career decision making (Kazi \& Akhlaq, 2017). As in career decisions, one has a parental, media and peer influence as well as financial constraints. But with all these external affects, one's own internal affect also have major impact most importantly their self-esteem. To find out the effect of selfefficacy on one's career decision making a research was conducted on students of national college Dragos Voda on students of age 19-21 which included both females' and males. In the study there was no correlation between career decision making and gender but a strong correlation was found between self-efficacy and gender. 
It was found that females have more self-efficacy due to which they made better career decisions and faced less difficulty while the male participants had less self-efficacy due to which they faced more issues and it was difficult for them to make any career decision (Crişan \& Turda, 2015). Similarly, another research indicated the role of self-esteem in career decision making that students who have high self-esteem in turn suffer from low career uncertainty as compared to students who have low self-efficacy that causes them to have highly uncertain about their career and so they face difficulty in deciding as to which career is appropriate for them and they face hard time in exploring their interests as compared to students who have high self-efficacy, who decide their interests careers earlier (Lin, Wu \& Chen, 2015)

Information Gap: There has been a lot of research regarding career decision making among adolescents, but they all are done in the west and none in Pakistan except one study that was also only restricted to the sources affecting student's career choices. Also, in west most of the research is done on age group 18-20 while this research targeted age group 18-24. It can be understood from the literature review mentioned in this report as well that serves as a proof that this research addressed a new problem and no research is done previously in Pakistan, Rawalpindi specifically on this topic.

\section{Hypothesis}

- Difficulties faced by adolescents in making a career decision negatively impact their mental health.

- Parental pressure affects adolescent career decision making.

- Peer pressure affects adolescent career decision making.

\section{Theoretical Framework}

Social Cognitive Theory: In reference to the research title impact of difficulties faced by adolescents in career decision making on their mental health, the social cognitive career theory explains the reasons of career decision making difficulties as to why does an adolescent faces this difficulty and how it affects his decision-making capacity. The social cognitive theory developed by Robert W. lent, Steven D. brown and Gail Hackett in 1994 (Lent, Brown \& Hackett, 1994) focuses to explore career choices as how our career and educational interests develop, then how we make a career choice and then how we obtain success in that career. All these three depend on our self-efficacy, outcome expectations and goals. So here we can relate this theory to our research topic. As an adolescent sets a goal, he continues to pursue it according to his selfefficacy. If he thinks that he is capable of pursuing medical after intermediate he will work hard and take admission into it. Now here also the outcome expectations come into play.

No matter how high his self-efficacy is, if the outcomes associated with his action will be negative; like if he receives criticism from his parents or friends then he will be less likely to pursue that career but if the outcome is positive then he will likely be pursuing the field. He is not able to take stand for his decision as he is not mature (age), sometimes due to gender as it limits their opportunities and each gender has their own way of tackling with the issues (Moderating variables). Also, sometimes he is emotionally attached to his parents or other people due to, which he fears losing that attachment. This all causes stress (mediating variables). So now according to the outcome, his self-efficacy either goes up or goes extremely down. That is the reason that causes indecisiveness and affects a person mentally. As what he has set to achieve that is his goal, is not having a positive outcome from the people around him that is ultimately causing his self-efficacy to get low and in turn he suffers mentally.

\section{Methodology}

This was a quantitative research method in which an online survey was used to collect data. It was a cross sectional research aimed to be completed within one month. The study was done in two parts; a pilot and a main study. The pilot study was used to check the reliability of the questionnaire that was found to be right. The sample for the pilot study was taken from the adolescents in Rawalpindi via an online survey. The sample consisted of 10 adolescents between the ages 18-24 who were enrolled in their bachelors. The sample for the eventual study was of the same age but the pilot study sample was not included in the eventual study as it was just done to check the questionnaire's reliability. The eventual sample was same of adolescents age 18-24 
in Rawalpindi both boys and girls. The sample size was 70. Random sampling method was used with the main purpose to highlight that career decision making is a major issue and it is being faced by every adolescent in today's time and not just specific ones. So, these all were combining together to affect the dependent variable of the research that was the mental health as a good correlation was found between career.

Ethical Consideration: As the data was collected through an online survey so the detail on the survey was mentioned and the respondents were informed that the data will only be used for a research purpose and it will not be misused. They were free to fill in the questionnaire or not.

\section{Results}

The findings are described below.

Table1: Reliability Statistics

Cronbach's Alpha $\quad$ N of Items

.813 23

The above table shows the reliability of the eventual data in which the Cronbach's alpha is .813

Table 2: Frequency and Percentage of the Gender of the Respondents

\begin{tabular}{lcl}
\hline Gender & F & \% \\
\hline Male & 28 & 40.0 \\
Female & 42 & 60.0 \\
Total & 70 & 100.0 \\
\hline
\end{tabular}

The above table shows the gender of the respondents. $40.0 \%$ of the respondents belong to male gender and $60.0 \%$ of the respondents belong to female gender. So, the data shows that majority of the respondent belonged to female gender i.e. $60.0 \%$

Table 3: Frequency and Percentage of the Age of the Respondents

\begin{tabular}{lll}
\hline Age & F & \% \\
\hline $18-20$ & 42 & 60.0 \\
$21-22$ & 16 & 22.9 \\
$23-24$ & 12 & 17.1 \\
Total & 70 & 100.0 \\
\hline
\end{tabular}

The above table shows the age of the respondents. $60.0 \%$ of the respondents belong to age $18-20,22.9 \%$ belong to age $21-22$ and $17.1 \%$ belong to age $23-24$. So, the data shows that majority of the respondents belonged to age group $18-20$ i.e. $60.0 \%$.

Table 4: Descriptive Statistics of Career Indecisiveness

\begin{tabular}{lllllc}
\hline & N & Minimum & Maximum & Mean & Std. Deviation \\
\hline Career indecisiveness & 70 & 10.00 & 20.00 & 13.9286 & 2.06644 \\
\hline
\end{tabular}

The above table shows the mean of career indecisiveness to be 13.9286 that is closer to the minimum value i.e. 10.00. As the mean value is near the minimum value it indicates that the adolescents have career indecisiveness because option yes was numbered as 1 in the questionnaire, according to which this value is appropriate. 
Table 5: Descriptive Statistics of Mental Health

\begin{tabular}{lllllc}
\hline & N & Minimum & Maximum & Mean & Std. Deviation \\
\hline Mental health & 70 & 15.00 & 37.00 & 23.8828 & 4.95186 \\
\hline
\end{tabular}

The above table shows the mean of mental health to be 23.8828 that is closer to minimum value i.e. 15.00 in accordance with the hypothesis as the value yes was numbered as 1 in the questionnaire. Thus, it indicates that career decision making difficulties have an effect on adolescent mental health.

Table 6: Correlation between Career Indecisiveness and Mental Health

\begin{tabular}{llll}
\hline & No of items & $\mathbf{R}$ & $\mathbf{p}$ \\
\hline Career indecisiveness & 70 & .370 & .002 \\
Mental health & 70 & .370 & .002 \\
\hline
\end{tabular}

The above table shows correlation between career indecisiveness and mental health which shows the value of $\mathrm{p}$ to be .002 that is significant. Thus, career indecisiveness and mental health are correlated to each other.

Table 7: T Test of Career Indecisiveness and Gender of the Respondents

\begin{tabular}{lllllll}
\hline & \multicolumn{1}{c}{ Male } & & Female & T & p \\
\hline Gender diff & Mean & SD & Mean & SD & 2.347 & 0.001 \\
& 41.6429 & 9.01527 & 37.4762 & 5.85699 & & \\
\hline
\end{tabular}

DF: $79, \mathrm{P}<0.05$

The above table shows $t$ test for career indecisiveness of both genders. The mean for male respondents is 41.6429 and standard deviation is 9.01527 while the mean for female respondents is 37.4762 and standard deviation is 5.85699 . The value for $\mathrm{T}$ is 2.65 and value of $\mathrm{p}$ is 0.001 . It shows that there is significant difference between genders regarding career indecisiveness. As $\mathrm{p}$ is less than 0.005 .

Table 8: ANOVA Test between Age and Career Indecisiveness of the Respondents

\begin{tabular}{lllll}
\hline & DF & Mean square & f & p \\
\hline Between groups & 2 & 55.121 & .976 & .382 \\
Within groups & 67 & 56.453 & & \\
\hline
\end{tabular}

The above table shows the relationship between career indecisiveness and age of the respondents. It shows that $\mathrm{p}$ is more than 0.005 i.e. .382 which shows that there is no significant difference between age and career indecisiveness.

Table 9: Cross Tabulation and Chi-Square Test of was Career Decision Making Time Period Stressful for you and were you Stressed When You Could Not Meet Your Parents' Expectations in Choosing a Career

\begin{tabular}{|c|c|c|c|c|c|}
\hline \multirow{2}{*}{$\begin{array}{l}\text { Was career } \\
\text { decision } \\
\text { making time } \\
\text { period stressful } \\
\text { for you? }\end{array}$} & \multicolumn{3}{|c|}{$\begin{array}{l}\text { Were you stressed when you could not meet your } \\
\text { parents' expectations in choosing a career? }\end{array}$} & \multirow{2}{*}{$\begin{array}{c}\mathbf{X 2} \\
31.381\end{array}$} & \multirow{2}{*}{$\begin{array}{l}\mathbf{p} \\
.000\end{array}$} \\
\hline & & f & $\%$ & & \\
\hline & Yes & 45 & 64.3 & & \\
\hline & No & 20 & 28.6 & & \\
\hline & Maybe & 5 & 7.1 & & \\
\hline
\end{tabular}


The above table shows chi square values for two questions indicating a strong $\mathrm{p}$ value of .000 which shows that parental expectations effect adolescents career decision making due to which adolescents get stressed. Thus, parental expectations are one of the factors effecting career decision making.

Table 10: Cross Tabulation and Chi Square Test of was Career Decision Making Time Period Stressful for you and do you think that seeing your Friends Choosing a Career that is Appreciated by Everyone Made you Feel Incompetent

\begin{tabular}{|c|c|c|c|c|c|}
\hline \multirow{2}{*}{$\begin{array}{l}\text { Was career } \\
\text { decision } \\
\text { making time } \\
\text { period stressful } \\
\text { for you? }\end{array}$} & \multicolumn{3}{|c|}{$\begin{array}{l}\text { Do you think that seeing your friends choosing a } \\
\text { career that is appreciated by everyone made you } \\
\text { feel incompetent? }\end{array}$} & $\mathrm{X} 2$ & $\mathbf{p}$ \\
\hline & & f & $\%$ & 17.462 & .002 \\
\hline & Yes & 22 & 31.4 & & \\
\hline & No & 37 & 52.9 & & \\
\hline & Maybe & 11 & 15.7 & & \\
\hline
\end{tabular}

The above value shows chi square values for two individual questions indicating a strong value of p i.e. .002 which shows that peer pressure is one of the factors which affects an adolescent's career decision making causing stress.

Table 11: Cross Tabulation and Chi Square Test for was it Difficult for you to make a Decision to Choose, this Career and was Career Decision Making Time Period Stressful for you

\begin{tabular}{|c|c|c|c|c|c|}
\hline $\begin{array}{l}\text { Was it difficult } \\
\text { for you to make } \\
\text { a decision to } \\
\text { choose this } \\
\text { career? }\end{array}$ & \multicolumn{3}{|c|}{$\begin{array}{l}\text { Was career decision making time period stressful } \\
\text { for you? }\end{array}$} & $\mathrm{X} 2$ & $\mathbf{p}$ \\
\hline & Yes & 56 & 80.0 & & \\
\hline & No & 10 & 14.3 & & \\
\hline & Maybe & 4 & 5.7 & & \\
\hline
\end{tabular}

The above table shows chi square values for two individual questions. The value of $\mathrm{p}$ shows to be .000 which indicates that the more difficulty adolescents face in making a career decision the more the decision-making time period gets stressful for them. It shows that career decision making difficulties affect adolescents psychologically by causing them stress.

Discussion: As according to social cognitive career theory, one's career choice, educational interest and success in that career depends upon his self-efficacy, outcome expectations and goals (Lent, Brown \& Hackett, 1994). From this study the adolescents reported that due to parental and peer pressure they faced difficulty in making a career decision which relates with the outcome expectations as the outcome that they were getting from their decision was not good which in turn effected their self-efficacy and then goal and also the more difficulties they faced, the more stressful career decision making time period was for them effecting their self-efficacy. So, these all were combining together to affect the dependent variable of the research that was the mental health as a good correlation was found between career indecisiveness and mental health. The moderating variables emotional attachment; as adolescents are affected by their parents and peer expectations and stress; as the career decision making time period is stressful for those adolescents who face difficulty in making a career decision, affect one's mental health. As well as the mediating variable gender is also found to effect the career decision making as there is a significant difference between the genders but at the same time age is not found to be a factor in career decision making difficulty and this interesting result reveals that a person of any age can go through this difficult phase it is not necessary that age as associated 
with immaturity is the cause to career decision making difficulties. As prior researches and literature review also suggested this and the results are in favor of it as studies found that parents pressure and perceived.

Control effects one's ability to make a career decision (Corey, 2015) another study found a positive correlation between peer and parental attachment and self-efficacy and negative correlation between peer attachment and career decision making as adolescents are influenced by their parents. Peer expectations and pressure that effects their decision making power (Hellmann, 2014) Studies also show that one's low selfesteem effect ones career decision making (Crişan \& Turda, 2015). The above discussion proves our hypothesis that difficulties in career decision making negatively impact adolescent mental health and that parental and peer pressure affects adolescents career decision making. So, there is a need for adolescents to be guided as they need a career guidance that can help them in deciding as what, are really their interest as studies have also shown that career guidance helps students in making a career decision (Kunnen, 2013)

\section{Conclusion and Recommendations}

Adolescents in Rawalpindi, Pakistan face difficulty in making a career decision that affects their mental health as the adolescents responded that career decision making was pressurizing and stressful for them and some of them were not even satisfied with the career, they are in. Also, their parent's expectations and peer pressure affect their career decision making which makes them stressed. The findings also suggested that male and female both face different difficulties and age does not define one's ability to make a decision. There is not a particular age in which difficulties will arise. This all shows that adolescents need a career guidance that can help them in deciding what they really want to do in their lives instead of making a wrong career and regretting it later. Thus, this research calls for a need of career guidance for the adolescents to help them out in knowing and understanding their interests and what they really want to do in their life and creating an awareness among them that who they really want to be. With these informative sessions need to be provided in the schools to make students think over their passions and interests from a basic level. And last but not the least, an awareness needs to be made in the society that no career Is inferior or superior and that pressurizing and forcing adolescents into a career that they do not want to pursue will only do harm to them and no good.

Limitations: As the research was supposed to be completed within a specific time period of 1 month so a diverse data collection was not possible. The quantitative sample was small and also not equal as females were 42 and males were 28 due to which the result cannot be generalized to the genders equally. So, there can be other factors affecting career decision making as well that this research could not found out.

Research Implications: In light of the above limitations, the research implications for this research are that for future research the sample should be large to have more insight into the issue and it should be equal to equally generalize the issue. Also, a qualitative research can be done to have more information about different adolescent's experiences. Also, the topic can also be molded and a better statement can be made by the future researchers.

\section{References}

Adolescence. (n.d.). In Merriam-Webster's collegiate dictionary.

Brown, S. D., Lent, R. W. \& Hackett, G. (1994). Social Cognitive theory.

Career. (n.d). In Oxford English dictionary.

Corey, P. (2015). Examining the influence of parental pressure and perceived control on young adult's career exploration.

Crişan, C. \& Turda, S. (2015). The connection between career indecision and perceived self-efficacy on career decision making among teenagers. Career indecision: Three factors from decision theory.

Guay, F., Senécal, C., Gauthier, L. \& Fernet, C. (2003). Predicting Career indecision: A self-determination theory perspective. Journal of counseling and Psychology, 50, 165-177.

Hellmann, J. (2014). Social and Psychological Factors related to Career Exploration process of Young Adults. Theses and Dissertations Family Sciences, 19.

Indecisive. (n.d). In Oxford Dictionary. 
Kazi, A. S. \& Akhlaq, A. (2017). Factors affecting students career choice. Journal of research and reflections in education, (2), 187-196.

Kunnen, E. S. (2013). Effect of career guidance on self-reported psychological problems. Department of developmental psychology.

Lin, S., Wu, C. \& Chen, L. (2015). Unpacking the role of self-esteem in career uncertainty: a self-determination perspective. Journal of positive psychology, 10(3), 231-239. 